\title{
A TECNOLOGIA DE INFORMAÇÃO E COMUNICAÇÃO COMO FERRAMENTA NO PROCESSO DE DESENVOLVIMENTO DA ESCRITA E LEITURA
}

\author{
Artemisa Piai Silva de Fernandez, Raquel Rosan Christino Gitahy \\ Universidade do Oeste Paulista - UNOESTE. Presidente Prudente, SP. E-mail: artemisapiai@gmail.com
}

\begin{abstract}
RESUMO
Este estudo objetivou analisar as influências das tecnologias da informação e comunicação e dos grupos de discussão no desenvolvimento e produção de textos dissertativos. Observamos um grupo de seis estudantes de um curso particular de redação, com idades entre dezoito e vinte e cinco anos. A metodologia adotada foi qualitativa participativa, e percorreu os seguintes momentos distintos: questionário inicial; primeira produção temática; discussão de grupo sobre o tema proposto, com utilização das TIC; segunda produção temática, e questionário final (autoavaliação). Conclui-se ao final que, o grupo de discussão auxiliou na aprendizagem colaborativa, proporcionando mais argumentos aos autores do texto. No desenvolvimento do pensamento crítico ficou evidente que o grupo de discussão aliado a tecnologia fez com que o aluno mostrasse conhecimento em seu texto escrito sobre o que estava dizendo; a quem estava dizendo; as estratégias de dizer e se colocasse como autor do texto.

Palavras-chave: Escrita. Texto Dissertativo. Tecnologia de informação e comunicação. Grupo de discussão.
\end{abstract}

\section{TECHNOLOGY INFORMATION AND COMMUNICATION AS A TOOL IN THE PROCESS OF WRITING AND READING DEVELOPMENT}

\begin{abstract}
This study aimed to analyze the influence of information and communication technologies, and discussion groups influence the development and production of dissertation texts. We observed a group of six students of a particular course of writing, ages eighteen until twenty-five years. The methodology used was participatory qualitative, and ran distinct moments: questionnaire, first thematic production; Group discussion on the theme, with use of information technology and communication; second thematic production and final questionnaire (self-assessment). It was concluded at the end that the discussion group assisted in collaborative learning, providing more arguments to the text's authors. The development of critical thinking was evident that the discussion group allied to technology has made the student show knowledge in your written text about what he was saying; who was saying; the strategies to say and stand as author of the text.

Keywords: Writing. Argumentative text. Information technology and communication. Group discussion.
\end{abstract}




\section{INTRODUÇÃO}

Por que o estudante não gosta de escrever? Em busca de respostas, analisei que nos últimos cinquenta anos, a percepção e o entendimento da vida, do mundo, da cognição mudaram radicalmente. Ao pesquisar as teorias do psicólogo americano Carl Roger (1951) se constata que, o ato de aprender não depende exclusivamente de características fisiológicas, mas também de aspectos emocionais, ambientais e relacionais que o aluno está inserido. $\mathrm{O}$ autor preleciona ainda que a educação é "uma procura excitante, uma busca, não a mera acumulação de fatos logo superados e esquecidos". (ROGER, 1973, p. 218)

No mesmo sentido se manifesta Moran (2014), que entende que a aprendizagem "exige envolver-se, pesquisar, ir atrás, produzir novas sínteses, é fruto de descobertas". E continua "só a aprendizagem viva e motivadora ajuda a progredir". (MORAN, 2014, p.34)

O século XXI possui uma fantástica forma de interação, que é a tecnologia. Possibilita interação em tempo real! Essa nova maneira de convivência social, possibilitada pelas TIC, é o que Levy (1993) denomina de cibercultura. Ou seja, uma cultura organizada em rede de comunicações. Diante deste novo cenário sócio-cultural, verifica-se que o processo de ensino e de aprendizagem contemporâneo apresenta-se desconectado da realidade dos "sujeitos aprendentes". E, nossas escolas ainda adotam práticas de atividades pedagógicas descontextualizadas, o que generaliza e mecaniza a língua portuguesa.

Neste contexto, o presente estudo objetivou analisar as influências das tecnologias da informação e comunicação e grupos de discussão no desenvolvimento e produção de textos dissertativos.

\section{Metodologia}

A presente pesquisa foi cadastrada no comitê de ética, na plataforma Brasil, sendo aprovada e recebendo o segundo número CAAE 31975114.3.0000.5515

A abordagem adotada foi a "qualitativa-participativa" com a adoção da técnica do grupo de discussão, além de questionários e produções de textos dissertativos.

O contexto onde foi realizada a pesquisa foi uma escola de Língua Brasileira e como sujeitos da pesquisa tivemos 06 (seis) estudantes, com idades entre 18 (dezoito) a 25 (vinte e cinco) anos. O presente estudo iniciou-se entre agosto e setembro de 2014, foi finalizado em dezembro de 2014. 
A primeira ação da pesquisa foi ministrar um questionário ao grupo estudado, com o objetivo de obter informações acerca do uso/interesse dos estudantes pela tecnologia fora do ambiente escolar. Verificamos que todos participam do mundo virtual.

Em seguida pediu-se ao grupo para realizar uma produção dissertativa. A primeira dissertação produção coletada foi elaborada na data de início de cada estudante.

$\mathrm{Na}$ terceira fase o grupo foi estimulado pela mediadora a pesquisar e discutir o tema. Para tanto, utilizam seus smartphones e tablets. Os participantes foram encorajados a falar, e a docente buscou as "deixas" de continuidade da própria discussão e fala dos participantes. O grupo de discussão implementado privilegiou as interações. Adotou-se as diretrizes de Mangold (1960, apud WELLER, 2006) que entende ser "um instrumento de exploração de opiniões coletivas [...]"

[...] a opinião do grupo não é a soma de opiniões individuais, mas o produto de interações coletivas. A participação de cada membro dá-se de forma distinta, mas as falas individuais são produtos da interação mútua [...] Dessa forma as opiniões de grupo cristalizam-se como totalidade das posições verbais e não verbais. (MANGOLD, 1960 apud WELLER, 2006, p. 245).

Aqui se iniciou a construção de relacionamento entre docente e o grupo, para aprofundar, individualmente, respostas e comentários considerados relevantes pelo grupo ou pelo pesquisador. Minayo (2007) entende que as discussões de grupo privilegiam uma maior inserção do pesquisador no universo dos pesquisados. O grupo de discussão rompe de vez com a visão unitária de conhecimento, entendido como algo pronto, acabado e pré-estabelecido. Após a discussão, o grupo conclui que a vida apresenta caminhos incertos, é imprescindível fazer escolhas conscientes das consequências.

No grupo de discussão foram apresentados dois vídeos e aproximadamente 5 minutos cada um. O primeiro apresenta um resumo da mini-serie da Rede Globo "Os Maias". E, "Orphan Black", minissérie da BBC.

Embasamos a presente abordagem em Moran (2000), que afirma que as potencialidades do vídeo fazem crer que esta ferramenta também tem uma "interatividade functional":

O vídeo é sensorial, visual, linguagem falada, linguagem musical e escrita. Linguagens que interagem superpostas, interligadas, somadas, não separadas. Daí a sua força. Somos atingidos por todos os sentidos e de todas as maneiras. O vídeo nos seduz, informa, entretém, projeta em outras realidades (no imaginário), em outros tempos e espaços. (MORAN,2000, p. 27).

$\mathrm{Na}$ quarta etapa pedimos a produção de outro texto e finalmente foi solicitado aos participantes que relatassem por questionário suas maiores dificuldades em relação a produção 
de texto dissertativo. Também pediu-se que informassem o tempo de curso, e suas opiniões sobre o quanto melhoraram na escrita. Ainda, quais os pontos que mais desenvolveu, e quais dificuldades que ainda persistem

Foram analisados os seguintes aspectos nos textos inicial e final:

1: Mudança da linguagem para a norma culta da língua, bem escrito: coerência (providencia a continuidade de sentido no texto e a ligação dos próprios tópicos discursivos), e coesão (oriente o leitor, mostrando o caminho da leitura). Para tanto, o texto deve apresentar: correta utilização de conectores; correta utilização da normal culta da língua; orações e períodos curtos e bem elaborados; não haver repetição de palavras; não utilizar gerundismo.

2: Aprendizagem colaborativa: grupo de discussão e método - como a pesquisa e discussão em grupo se reflete nos textos elaborados pelo grupo.

3: Desenvolvimento do pensamento crítico, elementos ligados ao contexto de produção (CAVALCANTI, 2010): 0 que dizer (tema a ser discutido) - elementos ligados ao contexto em que o texto será produzido; Estratégias de dizer (escolha de argumento e contra argumento) conhecimento sobre o assunto discutido; Para quem dizer (leitor pretendido pelo texto) - chamar atenção com seu texto não somente do professor que o corrigirá; Por que dizer (o que pretende o texto dissertativo?) - finalidade de convencer o leitor do ponto de vista adotado pelo autor.

Categoria 4: Indícios de autoria textual ou requisitos de "efeito de singularidade" Adotamos neste estudo o conceito de Possenti (2006 apud CAVALCANTI, 2010, p. 55, grifos nossos):

[...] para o analista, textos com autoria são aqueles em que é possível apreender a presença do autor que redige um trabalho, investindo no como dizer, na construção do texto. O sujeito-autor, por meio desse trabalho com a linguagem (que pode ser consciente ou não), confere ao texto um "algo mais" que pode ser explicado em termos de qualidade, elegância, consistência.

No final da pesquisa foi ministrado ao grupo um questionário auto-avaliativo e avaliativo do curso.

\section{RESULTADOS}

\section{Resultados Aluno 01}

Dificuldades verificadas texto inicial: Utiliza inadequadamente: conectores e linguagem coloquial; apresenta repetição de palavras; argumentação deficitária, proporcionadas pelas lacunas quanto a coerência e coesão, o que dificulta o convencimento de seu ponto de vista. 
Dificuldades iniciais percebidas pelo aluno 01: Questionário inicial: "sempre senti dificuldade em relação à escrita. Com o passar dos anos e a pressão dos vestibulares, me fizeram procurar um curso especializado no assunto a fim de melhorar esta prática".

Melhora verificada texto final: constatou-se melhora na utilização de conectores, eliminou-se a repetição de palavras e utilizou a norma culta da língua. Além de a argumentação apresentar fundamentos sólidos e elaborados. Na conclusão apresentou aspectos subjetivos do autor, o que caracteriza indícios de autoria textual.

Melhora percebida pelo aluno: Questionário final: Considera que melhorou $50 \%$ - "Sim, pois o meu rendimento escolar na disciplina da redação, também aumentou. Apesar da melhora na escrita das conclusões sinto que posso aperfeiçoar mais".

Avaliação do curso - Questionário final: Mais apreciou no curso "a capacidade de discussão dos temas, antes da resolução da redação".

\section{Resultados Aluno 02}

Dificuldades verificadas texto inicial: Utiliza inadequadamente: conectores e linguagem coloquial; apresenta repetição de palavras. Apresenta também, conhecimento epidérmico da estrutura dissertativa. Isso compromete a clareza de seu raciocínio, objetividade e desenvolvimento de pensamento crítico.

Dificuldades percebidas pelo aluno 02: Questionário inicial: "O principal motivo e melhorar a escrita e começar a me preparar para o vestibular. Espero que eu consiga me preparar bem!"

Melhora verificada texto final: constatou-se melhora na utilização da norma culta da língua, no uso de conectores e repetição de palavras. Estes aprimoramentos proporcionaram um texto mais coerente e coeso, representado por argumentações bem elaboradas e fundamentadas. $\mathrm{Na}$ conclusão apresentou aspectos subjetivos do autor, o que caracteriza indícios de autoria textual.

Melhora percebida pelo aluno: Questionário final: Melhorou 40\% - "Acho que estou começando a conseguir desenvolver mais minhas ideias. Considero que continuo com dificuldade em finalizar a dissertação".

Avaliação do curso - Questionário final: Mais apreciou no curso "o modo como a aula é dada".

\section{Resultados Aluno 03}

Dificuldades verificadas texto inicial: utiliza linguagem coloquial, emprego inadequado de conectores, elabora períodos excessivamente longos e apresenta gerundismo. A argumentação, apesar da elaboração de orações e períodos contraditórios ou confusos, apresenta coerência.

Dificuldades percebidas pelo aluno: Questionário inicial: "O principal motivo que me levou a iniciar o curso foi minha dificuldade em redigir textos dissertativos. Minhas expectativas em 
relação a ele são de melhorar minha escrita e aprender novas técnicas para argumentar, especialmente para fazer uma boa redação no vestibular".

Melhora verificada texto final: constatou-se melhora na utilização da norma culta da língua, emprego adequado de conectores. Melhora mas não supera os períodos longos e o gerundismo. No entanto, a melhora foi significativa, vez que sua argumentação foi bem elaborada e fundamentada. O texto apresenta coerência e coesão.

Melhora percebida pelo aluno: Questionário final : Melhorou 80\% - "Considero que melhorei: "em relação à demora na elaboração em relação a estrutura das redações e no desenvolvimento de argumentos".

Avaliação do curso - Questionário final: Mais apreciou no curso "a discussão dos argumentos em classe para o aumento de informações sobre o assunto".

\section{Resultados Aluno 04:}

Dificuldades verificadas texto inicial: o texto utiliza diversas impropriedades gramaticais, tais como o gerundismo e uso incorreto dos conectores. Sua argumentação apesar de coerente é superficial. A demonstração da insegurança argumentativa apresenta-se na articulação.

Dificuldades percebidas pelo aluno: Questionário inicial: "Ter uma melhor preparação para as redações dos vestibulares. Espero que o curso me ajude a desenvolver habilidades para escrever uma boa redação".

Melhora verificada texto final: constatou-se melhora quanto ao uso de conectores e gerundismo. Em decorrência sua argumentação foi segura e articulada. O Texto é coerente e coeso.

Melhora percebida pelo aluno: Questionário final: Melhorou 80\% - Considero que melhorei: "consegui criar meu estilo de pensamento, demonstrando minha opinião". Ainda apresenta dificuldade em "citar exemplos nas dissertações, o que as torna com pouco poder argumentativo". Avaliação do curso - Questionário final: Mais apreciou no curso "a clareza com que nos é apresentado os assuntos de cada aula do curso".

\section{Resultado Aluno 05}

Dificuldades verificadas texto inicial: uso inadequado de conectores e palavras com sentido incorreto. Também demonstra insegurança argumentativa, pois elabora períodos muito longos e confusos, o que compromete a coesão textual.

Dificuldades percebidas pelo aluno: Questionário inicial: "Eu comecei a fazer o curso de redação para me preparar para o vestibular".

Melhora verificada texto final: constatou-se melhora na utilização adequada de conectores e uso adequado da norma culta da língua. Apresenta períodos e orações bem elaboradas e menores. 
Estas conquistas transparecem no texto final, em que as argumentações são bem articuladas e fundamentadas. O texto final é coeso e coerente.

Melhora percebida pelo aluno: Questionário final: Melhorou 80\% - Considera que "melhorou bastante em relação ao começo do ano". Considera que ainda apresenta dificuldade "em relação à finalização do texto".

Avaliação do curso - Questionário final: Mais apreciou no curso é "a qualidade do curso".

\section{Resultado Aluno 06}

Dificuldades verificadas texto inicial: utilização inadequada de conectores, e apresenta linguagem coloquial. Apresenta frágil conhecimento da estrutura dissertativa, vez que o texto foi elaborado com somente três parágrafos. A argumentação insegura e ineficiente compromete o convencimento do leitor.

Dificuldades percebidas pelo aluno: Questionário inicial: "No vestibular a redação é um fator muito importante, decisivo para ingressar na instituição. Minhas expectativas eram as mais obvias possíveis, escrever conforme a norma culta da língua para ter um bom desempenho no ENEM e no vestibular".

Melhora verificada texto final: constatou-se melhora utilização adequada de conectores, e a norma culta da língua. Apresentou conhecimento da estrutura argumentativa, superando totalmente sua dificuldade inicial. Todo este crescimento colaborou para uma produção textual bem argumentada e fundamentada. O texto final é coeso e coerente.

Melhora percebida pelo aluno: Questionário final: Melhorou 50\% - "Melhorei bastante na introdução, conclusão e coerência. Mesmo tendo melhorado, eu tenho feito frases muito longas".

Avaliação do curso - Questionário final: Mais apreciou no curso "O aprendizado de algumas técnicas muito importantes para ter êxito no vestibular".

\section{DISCUSSÃO}

O grupo de discussão implementado privilegiou as interações. Adotou-se as diretrizes de Mangold (1960, apud WELLER, 2006) que entende ser "um instrumento de exploração de opiniões coletivas $[\ldots] "$

[...] a opinião do grupo não é a soma de opiniões individuais, mas o produto de interações coletivas. A participação de cada membro dá-se de forma distinta, mas as falas individuais são produtos da interação mútua [...] Dessa forma as opiniões de grupo cristalizam-se como totalidade das posições verbais e não verbais. (MANGOLD, 1960 apud WELLER, 2006, p. 245). 
A utilização das TIC possibilitou como expressa Freire (2014) uma "a assunção de uma posição crítica, vigilante, indagadora, em face da tecnologia. Nem, de um lado, demonologizá-la, nem, de outro, divinizá-la. (FREIRE, 2014, p. 133).

Nesta pesquisa observou-se que os estudantes entregaram-se nas aulas com participação, expressando seus pensamentos, ideias e raciocínio. Deslocou-se o estudante das aulas exclusivamente expositivas para aulas de construção, mudou, em curto espaço de tempo o perfil dos jovens pesquisados.

Os debates, análises, desenvolvimento de espírito crítico, descobertas e construções ocorreram de forma espontânea, chegando a surpreender os próprios alunos.

\section{CONCLUSÃO}

O objetivo central desta pesquisa foi investigar as influências das tecnologias da informação e comunicação e grupos de discussão no desenvolvimento e produção de textos dissertativos. Iniciamos, no segundo semestre de 2014, a observação sobre estudantes de um curso particular de redação preparatório para vestibular. Para tanto se adotou a metodologia pedagógica aberta, grupo de discussão, e a utilização das TIC. Estas estratégias tiveram como objetivo o estudante no centro dessa produção temática.

Para concluir volta-se a questão inicial: Por que o estudante não gosta de escrever e ler? Em todos os tempos houve estudantes que gostavam, e que não gostavam de escrever e ler. A diferença é que antes eles eram obrigados a ler, e liam, mesmo contra vontade. Hoje, o nativo digital não quer ser "obrigado" a nada. Ele quer ser convencido a... Quer interessar-se por... E elaborar por si mesmo.

A motivação do estudante, quando encontra situações desafiadoras, o instiga a se envolver mais profundamente na aprendizagem. Portanto, verificou-se que o objetivo desta pesquisa foi não só positivo, como surpreendente, diante dos resultados alcançados. Assim poderemos formar cidadãos pensantes, criativos, com espírito critico e que gostem de ler e capazes de escrever.

\section{REFERÊNCIAS}

CAVALCANTI, J. R. Professor, leitura e escrita. São Paulo: Contexto, 2010.

FREIRE, F. Pedagogia do oprimido. 54. ed. Rio e Janeiro: Paz na Terra, 2013.

. Pedagogia da autonomia: saberes necessários a prática educativa. 48. ed. Rio de Janeiro:

Paz e Terra, 2014. 
MINAYO, M. C. S. O desafio do conhecimento: pesquisa qualitativa em saúde.

10. ed. São Paulo: Hucitec, 2007.

MORAN, E. Os sete saberes necessários a educação do futuro. São Paulo: Cortez, 2000.

MORAN, E. Ensino e aprendizagem inovadoras com apoio de tecnologias. In: MORAN, J. M.; MASETTO, M. T.; BEHRENS, M. A. (Orgs.). Novas tecnologias e mediação pedagógica. 21. ed. Campinas: Papirus, 2014. p. 12-30. p. 11-72.

ORPHAN BLACK in 4 minutes. YouTube ${ }^{\mathrm{BR}}, 23 \mathrm{fev}$. 2015. Disponível em:

<https://www.youtube.com/watch?v=Ds5z5IVtY-8>. Acesso em: 03/04/2015.

OS MAIAS, Cenas finais parte 1(sem edição) Dirigido por Luiz Fernando Carvalho. YouTube ${ }^{\text {BR }}, 5$ jul. 2007. Disponível em: <https://www.youtube.com/watch?v=279yytFmgp0>. Acesso em: 02/04/2015.

ROGERS, C. Client-centered Therapy: Its Current Practice, Implications and Theory. Londres: Constable, 1951.

. Liberdade para aprender. 2. ed. Belo Horizonte: Interlivros, 1973.

WELLER, W. Grupos de discussão na pesquisa com adolescentes e jovens: aportes teóricos metodológicos e analise de uma experiência com o método. Educação e Pesquisa, São Paulo, v. 32. n. 2, p. 241-260, maio-ago. 2006. 